\title{
Derechos Humanos y Soberanía
}

\author{
Julio Juvenal Aldana Zavala \\ julioaldanazavala@gmail.com \\ https://orcid.org/0000-0002-7934-9103 \\ Universidad Nacional Experimental Francisco de Miranda \\ Venezuela \\ Josía Isea \\ josiaisea@gmail.com \\ https://orcid.org/0000-0001-8921-6446 \\ Universidad Nacional Experimental Francisco de Miranda \\ Venezuela
}

Recibido: 1 de marzo de 2018

Aprobado: 20 de junio de 2018

\begin{abstract}
RESUMEN
El análisis argumentativo sobre los derechos humanos y soberanía humana, se concibe con la finalidad de reflexionar sobre lo complejo que representan como fenómeno social, tanto los derechos humanos como la soberanía. Los derechos humanos, soberanía, globalización y deuda externa, son temas interconectados entre sí, lo cual índice en una correlación entre los mismos, la cual puede ser positiva si existe ciudadanía en capacidad de emprender acciones en progreso de su pueblo, será negativa en la medida que esta ciudadanía no exista y la sociedad se constituya en dependiente de agentes externos para trabajar en su desarrollo. Si se trastoca la soberanía, se violan los derechos humanos de las personas que habitan un determinado territorio, esta violación puede ser por el propio Estado o por Estados externos. Para ser soberanos es necesario contar con ciudadanos en conocimiento y cumplimiento de sus deberes y derechos constitucionales. La democracia y los derechos humanos se constituyen un entramado complejo, por cuanto sea el modelo de filosofía política que se desarrolle en un determinado país, será el manejo de los derechos humanos.
\end{abstract}

Descriptores: derechos humanos; soberanía; ciudadanía. 


\section{Human Rights and Sovereignty}

\section{SUMMARY}

The argumentative analysis on human rights and human sovereignty, is conceived with the purpose of reflecting on the complexities that represent as a social phenomenon, either human rights or sovereignty. Human rights, sovereignty, globalization and external debt are interconnected issues, which explain a correlation between them, that can be positive if there is citizenship capable of undertaking actions in progress of their people, and will be negative in the measure this citizenship does not exist and society becomes dependent on external agents to work on its development. If sovereignty is overturned, the human rights of the people who inhabit a certain territory are violated, this violation can be by the State itself or by external States. To be sovereign, it is necessary to have citizens in knowledge and fulfillment of their constitutional rights and duties. Democracy and human rights are a complex network, as the model of political philosophy that develops in a particular country, will be the management of human rights.

Descriptors: human rights. Sovereignty; citizenship.

\section{A modo introductorio}

Los derechos humanos universales, se constituyen en génesis de la globalización en beneficio de la humanidad, se encuentra establecido con anterioridad a la visión económica global que fundamenta el termino globalización tal como se conoce actualmente. El beneficiar al ser humano es el centro de los derechos humanos, para que pueda de modo individual y colectivo, generar acciones contundentes para lograr su propio progreso integral.

De ese modo, cuando la persona comprende el valor que tiene el mundo, puede formarse progresivamente hasta constituirse en ciudadano, actuación que le permitirá trabajar para la consecución de la soberanía de su Estado, prepararse para ser emprendedor, productivo, protagonista, del progreso integral de su sociedad en la medida que esta se constituye en garante del buen vivir, esto hace posible que la sociedad internalice la importancia que tiene la soberanía como elemento para transcender las deudas internas y externas, las cuales en ocasiones imposibilitan contar 
con países donde reine la igualdad, justicia, respeto, libertad, como ejes fundamentales de los derechos humanos.

Existe una dinámica interconexión entre los derechos humanos, soberanía y deuda externa, es una correlación que puede ser positiva o negativa según los resultados obtenidos en una determinada sociedad. Es importante formar conciencia colectiva desde los derechos humanos, solo así existirá una real posibilidad de contar con ciudadanos que trabajen sinérgicamente en lograr la soberanía de su nación.

La democracia, derechos humanos, se convierten en los pilares fundamentales para la defensa y promoción de la ciudadanía en la postmodernidad, son instrumentos para la gobernabilidad cívica de los pueblos, esto implica una opción como modelo de vida social para el ejercicio pleno de la sociedad globalizada del actual siglo. Sin embargo, como se ha manifestado en trabajos anteriores, tanto democracia como derechos humanos, tienen una carga subjetiva importante para su aplicación y cumplimiento por parte de los organismos públicos nacionales e internacionales.

La subjetividad viene planteada desde las esferas de interés de un determinado grupo socio político, es una mirada compleja que transita hacia la búsqueda de la objetividad para encontrar así, la posibilidad de equilibrio que permita confluir en un proceso real de aceptación y aplicación de los derechos humanos en ámbitos democráticos que pueden tener una vertiente liberadora, republicana, representativa, protagónica, en donde los derechos individuales transcienden los colectivos o viceversa.

Esto hace posible la generación de un entramado complejo de cara a los derechos humanos y democracia, el papel que juegue la ciudadanía en la sociedad, es primordial para desentrañar el camino que determine en realidad cual es el rol de los derechos humanos en una sociedad democrática, transciendo las visiones subjetivistas de interés parcelados sobre el bienestar colectivo, el cual debe ser el norte de los derechos humanos y por ende de todo democracia, el poder minoritario no debe relegar al poder colectivo, el cual es conformado por los ciudadanos en su ejercicio de su ciudadanía, dado que esto abre las brechas para comprender cuando existe o no, violación de la soberanía de un determinado país por parte de los organismos internacionales, defensores de los derechos humanos y de la democracia. 


\section{Derechos humanos y soberanía}

Los derechos humanos y la soberanía, son temas controversiales para los Estados Naciones, bien sean de corte democrático o absolutista, por cuanto el discurso jurídico internacional establece que los pueblos son soberanos ¿pero realmente que es ser soberano? ¿Cuándo un pueblo es realmente soberano? Podría señalarse a priori que se es soberano cuando su Estado tiene la capacidad de satisfacer las necesidades de su pueblo sin dependencia de otro Estado, sino en alianza o cooperación con otros Estados. La alianza o cooperación no es sinónimo de "dependencia", por cuanto esta se refiere al estado de indefensión o de espera que otro Estado provea lo necesario para poder garantizar la mayor suma de felicidad posible al pueblo.

Cuando un Estado (país) depende fielmente de las decisiones de otro Estado para poder garantizar las necesidades básicas al pueblo (alimentación, medicinas, seguridad, etc.,) entonces se constituye en un súbdito de este, en su esclavo, lo cual impide ser soberano no solo para tomar decisiones, sino, para brindar al pueblo los mecanismos para que este sea soberano. En contraposición, la alianza o cooperación entre Estados, permite que ambos se beneficien y establezcan una relación ganar ganar, esto no impide que exista soberanía en el pueblo, al contrario el Estado se constituye en un administrador de la soberanía emanada por el pueblo para que en su representación puedan diseñarse políticas públicas en procura de brindar la mayor suma de felicidad posible al pueblo.

Mayor suma de felicidad posible al pueblo, debe entenderse la capacidad que tiene el Estado de brindar a su población: Educación crítica, reflexiva, para la generación de ciudadanos, en este sentido, un ciudadano es quien se encuentra en la capacidad no solo de conocer sus deberes y derechos, sino de asumirlos, defenderlos, transcender a un modelo social que le permita la convivencia en armonía con sus semejantes, así como el ecosistema donde habita. Esto no implica estar en el cielo terrenal, por cuanto es utópico, pero si en una relación interpersonal que permita mediante el cumplimiento de leyes y normas establecidas, un vivir según el contrato establecido por los habitantes de un determinado territorio. En complemento a lo planteado, (Marshall 1998: 22) plantea que "la ciudadanía, como proceso histórico, se estructura a partir de tres 
elementos: civil, político y social”. En complemento de lo planteado, (Opazo, 2000: 58), señala que:

El término ciudadanía está integrado por dos elementos: a) cualidad y derecho de ciudadano y, b) la identidad de pertenencia a un pueblo. Estos mismos elementos se encuentran en la palabra citizenship que remite a: a) el estatus de ser ciudadano, y b) a la voz que refiere a la membresía de una comunidad.

En función de las consideraciones planteadas, la ciudadanía es soberanía y la soberanía es ciudadanía, ahora bien, esto implica que un pueblo es soberano cuando es ciudadano, ante lo cual el Estado, como administrador de la soberanía del pueblo, mediante las leyes establecidas, debe garantizar la mayor suma de felicidad posible al pueblo, dado que sin esto, difícilmente un pueblo podrá alcanzar la ciudadanía. Una vez alcanzada la ciudadanía, se generará la alianza y cooperación entre los Estados Naciones para el beneficio de ambos, dado que al no existir ciudadanía en uno de ellos, el Estado dominante transcenderá a alienar y culturizar a los no ciudadanos del otro Estado, enajenándose así la soberanía de este último.

La soberanía por consiguiente, juega un papel importante en el progreso integral de los pueblos, dado que no solo el alienante podrá ser un agente externo al Estado, sino que podría ser el propio Estado quien se encargue de dominar y no establecer la ciudadanía dentro de sus fronteras. Esto conlleva al establecimiento de un poder absoluto sobre el pueblo, generalmente al revisar los antecedentes históricos de las naciones que han tenido por gobierno el absolutismo, se visualiza una precaria ciudadanía en el pueblo, producto que no se garantiza en el mejor de los términos, la mayor suma de felicidad posible al pueblo.

Hemos visualizado hasta ahora, dos escenarios sociales, en uno existe soberanía y en otro no, en el segundo no se desarrollan eficazmente "los derechos humanos", por cuanto no existe "libertad", "soberanía", y por consiguiente "ciudadanía", en el pueblo, quedando este a merced de agentes externos o internos, así como una combinación de estos, los no ciudadanos que terminan por convertirse en esclavos posmodernos de un determinado gobierno o de intereses económicos dominantes. 


\section{Derechos humanos y globalización}

La globalización es un término que ha entrado al dominio público mundial desde la última década del siglo XX, sin embargo, la esencia de la globalización no es nueva y tiene su génesis en la idea de universalizar los derechos humanos, tal como lo expone (Gonzales, 1997: 99) "más allá de enfoques economicistas y de trampas intervencionistas, la globalización es un proceso que encuentra su primer motor, no en la llamada "fábrica mundial" ni en el "neoglobalismo" estadounidense, sino en la preocupación por los derechos humanos". La globalización de los derechos humanos se fundamenta en colocar al ser humano como centro, defender sus derechos de modo universal es sinónimo de girar hacia el respeto, igualdad, libertad, justicia, como garantes del buen vivir en colectivo.

La globalización como término en su esencia a finales del siglo $X X$, se basa en globalizar el comercio, expandir lo económico, tecnológico, esto genera competitividad entre las grandes corporaciones y empresas mundiales donde se genera la frase de los "tiburones grandes se comen a los peces pequeños", los pequeños deben complementarse para poder ser competitivos en un mercado voraz. El ser humano desde esta postura se constituye en centro en la medida que interactúa con el mercado y se fortalece con el mismo, lo contrario es signo de debilidad, pobreza, sub desarrollo, categorías que son contrarias a los "derechos humanos" desde una perspectiva del derecho natural del ser humano.

Hasta ahora se ha analizado el sistema económico mundial y su influjo desde la globalización, así como en los derechos humanos. Dentro de este sistema, se genera una relación a nivel subsistémico mediante el cual se construyen relaciones sociales en la sociedad que conforma un determinado país, esto en palabras de (Maddison, 1998) lo describe "a nivel subsistémico, es decir, dentro de las sociedades de los países, se observa un fenómeno de integración social, pero también de creciente discriminación y marginalidad económica en varios sectores".

Desde las posturas hasta ahora planteadas, se perciben categorías como discriminación y marginalidad económica, esto implica que no necesariamente la globalización trae consigo beneficios, riquezas, a las sociedades, según el grado de 
ciudadanía existente, se podrá consolidar una integración que beneficie al pueblo desde la visión de la mayor suma de felicidad posible, no contar con ciudadanía, es correr el riesgo de ser esclavo de la miseria, marginalidad, discriminación, generada desde una visión global económica que priva en su esencia sobre los derechos humanos universales, solo la educación encausada a formar ciudadanos, puede generar empresarios y un comercio con una visión humanista.

La globalización debe estar en consonancia con los derechos humanos universales, al existir disociación se corre el riesgo de generar discriminación, marginalidad, pobreza, desigualdad, injusticia, al existir asociación, puede fomentarse una sociedad activa, protagónica, ciudadana, emprendedora, respetuosa de las leyes y normas, para así establecer una convivencia generadora de riqueza espiritual, material, para equilibrar a la ciudadanía hacia un buen vivir, los países se encaminaran hacia un progreso integral de modo sistemático, lo cual redunda en defensa de los derechos humanos universales.

\section{Derechos humanos y deuda externa}

Los derechos humanos y deuda externa, son temas que tienen implícito la soberanía, así como la globalización. Soberanía en cuanto los países latinoamericanos históricamente como deudores de la deuda externa, han tenido en cierto modo socavar su soberanía en ocasiones para obtener el crédito y posteriormente el refinanciamiento de la misma, así como recursos que podrían ser usados para la inversión social interna, son destinados para cancelar intereses de la deuda externa, la cual parece ser impagable, esto ocasiona un circulo viciosos en donde la miseria, desigualdad, bajos salarios, son algunos de los detonantes para deconstruir la soberanía, ciudadanía, de la sociedad, el Estado se imposibilita en ocasiones para revertir esta situación, generándose brechas que promueven la pobreza. En palabras de la Red Europea sobre Deuda y Desarrollo (EURODAC, 1991: 7) señala que:

Los elevados montos de la deuda externa colocaron a los países deudores en una situación crítica que se reflejó en que los ingresos de divisas provenientes de las exportaciones de sus principales productos, se destinaron cada vez más al pago de la deuda, lo que generó tensiones sobre la balanza de pagos y dificultó la importación de bienes esenciales. 
Asimismo, los recursos que los Estados debieron haber orientado a la formación de capitales para impulsar la inversión y el desarrollo, así como también a atender servicios esenciales como la educación, la salud y el empleo, fueron absorbidos por el pago de la deuda. Esto agravó los niveles de desempleo, marginalidad y pobreza crítica que caracterizan a las actuales sociedades latinoamericanas.

A pesar de que los derechos humanos, prevén que ninguna deuda externa se encuentra magnificada en detrimento de los bienes fundamentales de una nación, esta debe generar los mecanismos para brindar al pueblo las posibilidades de progresar en la medida que cancela su deuda externa. En este sentido:

La Comisión de Derechos Humanos de Naciones Unidas, en 1993 afirmó que "los Pagos de la deuda no deben tener prelación sobre los derechos básicos de la población de los países deudores a la alimentación, alojamiento, vestido, empleo, servicios de salud y un medio ambiente saludable".

Debe existir responsabilidad recíproca entre quien solicita el préstamo y la entidad que lo emite, dado que un país no puede endeudarse más allá de sus capacidades reales de pago, debido que esto es condenar a su población a sufrir pobreza, discriminación, e incluso pérdida de su soberanía. Esto redunda en el tema comercial de la globalización, por cuanto las naciones pobres y deudoras, estarán condenadas a ser los peces pequeños que serán devorados por los tiburones, casi sin posibilidad de fomentar un real progreso en sus pueblos, debido que no serán países atractivos complementariamente a las exigencias globales de la economía, es decir, no serán socios de las grandes potencias, sino esclavos u olvidados, generándose una brecha que proyecta que el Estado por consiguiente, no es soberano en realidad de su entorno social.

\section{Democracia y Derechos humanos}

La democracia y los derechos humanos representan un fenómeno político de connotada complejidad, dado la relación que se genera entre ambos según la vertiente filosófica política desde la cual se perciba, oriente, el entramado democrático gerencial de la democracia en un determinado contexto país o Estado. La visión política del 
liberalismo, representa una opción que privilegia los derechos individuales sobre los colectivos, además le brindan mayor énfasis a los derechos políticos y civiles; mientras que la vertiente republicana enarbola la bandera de los derechos colectivos, aunado a los derechos económicos, sociales, culturales, del colectivo, procura la participación ciudadana protagónica como gestión local para la construcción de políticas públicas que beneficien el bien común. En este sentido, (Villaseñor, 2015: 1118), establece lo siguiente:

Es así que la democracia, pensada desde las distintas filosofías políticas, adquiere distintas posturas hacia los derechos humanos. Mientras que al liberalismo libertario le bastan los derechos civiles y políticos, el republicanismo demanda el desarrollo cabal de los individuos, que a su vez requiere del cumplimiento de los derechos económicos, sociales y culturales. Esto es así porque el desarrollo integral de los individuos requiere necesariamente de una buena salud, educación y pertenencia a sistemas culturales, para lo cual se requieren acciones positivas mediante políticas públicas que garanticen estos derechos a todos los individuos.

Los derechos humanos desde lo planteado, son procesados de acuerdo a la visión democrática generada en un Estado, esto implica que desde la perspectiva de soberanía de ese Estado, se aceptará o no el cumplimiento de los derechos humanos en el territorio desde un contexto privilegiado hacia un grupo de derechos (políticos civiles. Económicos - culturales - sociales) o la integración de todos como un ente que beneficie al colectivo, esto último desde la significancia aceptada sobre los derechos humanos. La segunda relación entre democracia y derechos humanos que hace posible un entramado complejo, se encuentra en el orden si la democracia es representativa o protagónica, dado que son visiones diferenciadas principalmente por el papel que juega la ciudadanía como protagonista en cada uno de los modelos. En cuanto a lo representativo, (Vargas, 2013: 1) señala que:

La democracia representativa fue el modelo clásico de participación política que se configuró, asociada al surgimiento del Estado Nación moderno, por razones de diverso tipo tamaño de los territorios, imposibilidad de participar de todos los ciudadanos, restricciones a la participación asociados a mecanismos como el denominado voto censitario y esto a su vez estuvo ligado al surgimiento de los partidos políticos expresivos de corrientes de opinión política diferenciadas- como mecanismo privilegiado para escoger a 
los representantes. Esto, acompañado del rol jugado por los grupos de interés fue durante mucho tiempo la forma de participación política en las democracias occidentales.

La participación ciudadana en la democracia representativa, principalmente se ve cristalizada mediante el voto de elección de los gobernantes, es allí en donde el pueblo cede el derecho a un grupo de representantes para que dirijan los destinos políticos, civiles, económicos, culturales, sociales, del Estado, ante lo cual, el gobierno se genera en función de los intereses de la elite gobernante y no de la ciudadanía, debido que generalmente en este tipo de democracia la participación ciudadana se encuentra en los primeros eslabones de participación, donde realmente no ocurre una real participación, tal como lo plantea (Sherry Arnstein, 1971) en su escalera de la participación ciudadana.

La democracia participativa, aunque no ha generado transformación jurídica en la figura moderna del Estado - Nación, surge como una visión emergente dentro de este, como contraparte de la representatividad, privilegiando así, al ciudadano como protagonista del accionar político del Estado. En este sentido, el portal (democracia participativa, 2015:1) señala que:

La democracia participativa implica el papel activo de los ciudadanos en el funcionamiento de la democracia, mediante mecanismos establecidos en una sociedad civil libre que permitan su manifestación y una efectiva participación en la toma de decisiones. Es una democracia en la que todos los ciudadanos son protagonistas.

No se pierde el derecho y poder al voto para la elección de los gobernantes, solo que en este modelo se crean los mecanismos constitucionales, jurídicos, para que el pueblo organizado tenga una participación activa, protagónica, en la construcción y aplicación de las diversas políticas públicas, generándose un proceso de gobernanza donde la participación comunitaria juega un papel esencial como sustento de la democracia.

Desde ambos modelos se manejan los derechos humanos con diversos enfoques, en el primero, es el Estado quien articula el cumplimiento de los derechos, en el segundo, la ciudadanía promueve la defensa y promoción de los derechos humanos. En lo 
representativo existe una participación primordialmente pasiva por parte de la ciudadanía, es decir se constituyen en receptores, dado que son las elites y organismos jurídicos (gubernamentales o no), los encargados de articular las acciones sobre los derechos humanos, en cambio en lo protagónico, el pueblo adquiere la posibilidad de ser emisor, teniendo el poder de promover la retroalimentación entre los diversos organismos que conforman el Estado, en pro de los derechos humanos como ente esencial para el sustento de la democracia.

\section{Carta Interamericana, democracia y derechos humanos.}

La carta interamericana no es un tratado internacional, es articulado político - jurídico de libre aceptación de los países que conforman la Organización de los Estados Americanos (OEA), mediante la cual se busca garantizar la existencia de la democracia en las naciones firmantes y adheridas a la carta interamericana. En este sentido, la (OEA, 2016: 1) plantea lo siguiente:

Esta capacidad de sancionar a los Estados Miembros que sufran rupturas institucionales, repetida y ampliada en la Carta Democrática Interamericana, es inédita en el mundo: aún hoy, sólo en las Américas (la OEA y las organizaciones subregionales que adoptaron la también llamada "cláusula democrática") la contemplan en su acervo jurídico.

Esto implica que los Estados firmantes de la carta interamericana, pueden ser sancionados según los términos establecidos en la misma, si se demuestra ruptura en el hilo democrático de gobernabilidad del país miembro. Esto genera las bases para que los países que violen los derechos humanos, puedan ser sancionados, debido a lo contemplado en la (Carta Interamericana, 2001) en sus artículos:

Artículo 3: Son elementos esenciales de la democracia representativa, entre otros, el respeto a los derechos humanos y las libertades fundamentales; el acceso al poder y su ejercicio con sujeción al estado de derecho; la celebración de elecciones periódicas, libres, justas y basadas en el sufragio universal y secreto como expresión de la soberanía del pueblo; el régimen plural de partidos y organizaciones políticas; y la separación e independencia de los poderes públicos. Artículo 7: La democracia es indispensable para el ejercicio efectivo de las libertades fundamentales y los derechos humanos, en su carácter universal, indivisible e interdependiente, 
consagrados en las respectivas constituciones de los Estados y en los instrumentos interamericanos e internacionales de derechos humanos. Artículo 8: Cualquier persona o grupo de personas que consideren que sus derechos humanos han sido violados pueden interponer denuncias 0 peticiones ante el sistema interamericano de promoción y protección de los derechos humanos conforme a los procedimientos establecidos en el mismo. Los Estados Miembros reafirman su intención de fortalecer el sistema interamericano de protección de los derechos humanos para la consolidación de la democracia en el Hemisferio.

La carta exhorta al desarrollo del modelo de la democracia representativa, esto le brinda poder al Estado y sus organizaciones autorizadas como entes para la defensa y promoción de los derechos humanos, quedando relegado la participación ciudadana en el tema de los derechos a la pasividad, es decir cuando sus derechos sean violentados podrá acudir ante un determinado organismo, aunque la carta prevé la posibilidad de realizar tal denuncia en organismos supranacionales.

Es allí donde se genera la disyuntiva entre el Estado y lo supranacional, por el tema de la soberanía, es de preguntarse ¿Cuándo realmente se puede aplicar la carta interamericana a un país? ¿Desde qué vertiente se establece que se ha violado la democracia o los derechos humanos? ¿La violación individual de los derechos humanos priva para que pueda existir activación de la carta interamericana? ¿Debe existir una violación masiva de los derechos humanos para activar la carta interamericana? Son premisas que este papel de trabajo no tendrán repuestas, sino que son generadores de reflexión para el lector, lo que si es cierto es que parece que la aplicación de la carta interamericana a un determinado país, se establece en la medida que los intereses internos o externos al mismo, lo permitan.

Esto abre las puertas de discusión entre la OEA y un determinado Estado, sobre si existe violación de los derechos humanos o de la democracia del mismo, es decir, cuando se hace realmente tangible al pueblo una medida de este tipo. Por cuanto podría realmente existir violación colectiva de los derechos humanos y el Estado enarbolando la soberanía niega la existencia de tal violación o por el contrario, podría no existir pero podría desarrollarse una intervención como una acción de intereses geopolíticos, lo cual si violaría la soberanía. Esto genera un proceso complejo para 
brindar una repuesta asertiva, contundente, ante el hecho de que se estén violando los derechos humanos en una nación.

\section{Derechos humanos y seguridad nacional. Victimalidad y criminalidad.}

Los derechos y seguridad nacional es una vertiente compleja, por cuanto se remite al tema de soberanía, tanto interna como externa al Estado - Nación, por cuanto la seguridad debe estudiarse desde los movimientos sociales intrínsecos, los cuales al no ver favorecido sus condiciones de progreso integral, buen vivir, desarrollo, calidad de vida, suprema felicidad, entre otras acepciones; se generará inconformidad creadora de problemáticas como el hambre, delincuencia, prostitución, drogas, contrabando, migración, corrupción, salarios indignos en la clase trabajadora, promoviéndose un caldo de cultivo para la implosión colectiva de la sociedad en sus valores esenciales que le permitan constituirse en un ser humano.

Desde lo planteado, existe una sistemática violación a los derechos fundamentales del ser humano, promoviéndose un círculo vicioso en donde los roles y liderazgos sociales son invertidos, es decir, cuando la sociedad va en detrimento de su dignidad, justicia, se desarrolla un desequilibrio emocional - espiritual que hace pensar a quienes no tienen una formación o educación centrada desde cuadros axiológicos fortalecidos, según los cánones socialmente aceptables en el marco jurídico vigente, terminan por percibir que son las acciones negativas las que privan sobre las que realmente son positivas.

Esto visibiliza a muchos jóvenes de estratos sociales diversos a considerarse seguidores de líderes negativos, en las comunidades más desfavorecidas, los jóvenes juegan a ser PRANES, en los más alto desde el punto de vista económico, lo hacen pensando en ser PRANES de CUELLO BLANCO, dos polos socioeconómicos opuestos que en el fondo recrean en su imaginario social ser líderes negativos. Desde esta concepción imaginaria, se va recreando una sociedad en donde los valores humanos, sociales, se constituyen en un mero accesorio el cual es utilizado según sea la pertinencia de los mismos, posibilitando la progresiva implosión social de la sociedad venezolana, en función de lo planteado, (Martorano, 2017:1) explica lo siguiente: 
Me señalaba el compañero y amigo que el término PRAN, mediática y comunicacionalmente nos lo venden como "aséptico", y muchas series televisivas nos lo venden como un tipo "chévere" que tiene las mejores "chicas", dinero, se viste bien, tiene los mejores carros, y es el más arrecho del barrio. Nos muestran a estos "señores" como modelos a imitar y a seguir.

El imaginario social negativo de la colectividad va cooperando a un progresivo deterioro axiológico de la percepción sobre la defensa, promoción, de los derechos humanos, sobre todo aun, de los valores que permiten crecer de modo individual - colectivamente como una nación moralmente asertiva. Este proceso descrito, trastoca medularmente la seguridad nacional a lo interno del Estado - Nación, por cuanto es el liderazgo negativo quien prevalece sobre el positivo.

Una segunda vertiente que afecta la seguridad nacional, es la externa al Estado Nación, esto implica desde la transculturización de los pueblos hasta las elites de poder económico que buscan hacerse del control de un determinado país. Esto ocurre cuando se establecen grupos de control subsidiarios del poder gubernamental local, es decir socio económico y político que colonializan a una sociedad, esto es violatorio de los derechos humanos, dado que no existe una real gobernabilidad sobre el pueblo, sino que se hace en función de complacer los intereses, necesidades, del grupo control externo.

Llegado a este punto el Estado - Nación se confronta entre dos polos diametralmente opuesto pero que comparten un mismo fin, el cual es dominar desde liderazgos negativos, a la población que se encuentra en medio de ambos, para esto es necesario destruir progresivamente sus derechos fundamentales basados en los derechos humanos, es recrear el imaginario social hacia una percepción colectiva que el control y dominio lo tienen precisamente los negativos y no los positivos.

Cuando un Estado - Nación se encuentra navegando en aguas turbulentas como la planteada, simplemente queda a la deriva a la merced que uno de los tres polos (colonizadores, clase media, líderes negativos), pueda revelarse y tomar el control total de la sociedad. Mientras convivan entre sí, existirá un caos en donde la violación de los 
derechos humanos, será el alimento de cada día para una sociedad consumida por la violencia sistemática de sus más elementales derechos.

Por consiguiente, el tema de los derechos y seguridad nacional es complejo, no puede solo estudiarse desde la consecuencia, es decir, del acto final que conlleva a violar los derechos humanos, por ejemplo un delincuente que comete un determinado delito. Ciertamente al cometer delito, viola los derechos humanos de la víctima, pero la pregunta es ¿cómo se convirtió en delincuente? A priori es imposible brindar una repuesta certera, pero en el hacer conjeturas, seguramente se puede señalar que todos los que violaron los derechos humanos del delincuente son los responsables de tal acto, de modo que una sociedad que permite sistemáticamente sean vulnerados sus derechos humanos, está condenada a padecer las consecuencias de tal violación.

\section{Terrorismo y desarrollo científico}

Desde el terrorismo y desarrollo científico, puede generarse nuevos modelos de violación de los derechos humanos, gestación de criminalidad y victimalidad a gran escala, esto cuando se utiliza el conocimiento científico para dañar al ser humano, violar soberanías, en la medida que se construyen guerras para encausar invasiones en nombre de la libertad. Estas guerras pueden ser de índole religiosa, cultural, económica, política, entre otros factores determinados por los grupos de poder que proyectan libertar al mundo.

Estos escenarios terroristas son contrarios a la vida humana, a la libertad, por consiguiente se constituyen en un efecto dominó violatorio del resto de los derechos humanos, trastoca la dignidad humana, por cuanto no se entiende que el mundo es diverso, la unificación de razas, pensamientos, por un grupo dominante ha configurado la muerte, tal como ocurrió con la experiencia nazi de la segunda guerra mundial. En ese contexto, ciertamente se dieron grandes avances científicos, lo cual hoy crea un dilema ético sobre si fueron necesarios para que la humanidad de hoy, goce de muchos de esos avances, sobre todo en el campo de la medicina, no es razón de este papel de trabajo descifrar tal dilema, pero sí brindar un espacio para la reflexión, el cual radica en pensar que detrás de una guerra, de un acto terrorista, de un avances científico, existen 
intereses de diversos índoles, siendo estos los que terminan por violar los derechos humanos.

Por cuanto el acto en sí, es una consecuencia de una acción planificada, pensada, por grupos dominantes que aspiran dominar, controlar, la humanidad. Solo en el imaginario controlador de quienes planifican este tipo de acto, se desarrolla el génesis de la violación de los derechos humanos, por cuanto ¿quién tiene el derecho de dominar y esclavizar a otro? El pensar así, es creerse Dios en la tierra, aunque desde la concepción cristiana Dios brinda libre albedrío al ser humano para que piense y actúe según su conciencia, lo cual implica que las mentes criminales pretenden estar por encima de Dios o al margen del mismo.

Entonces desde que concepción de defensa de los derechos humanos, la criminalidad organizada a altos niveles de terrorismo, actúa realmente, cuando son sus intereses y no los colectivos los que privan. Vislumbrándose desde esa actuación, la no coexistencia con el respeto, diálogo, aceptación del otro, libertad, progreso, entonces ejecutan avances científicos y comenten actos terroristas en detrimento de la humanidad, nunca en pro de su emancipación real, constituyéndose así, en unos flagrantes violadores de los derechos humanos fundamentales de la persona.

\section{A modo de reflexión:}

- El tema de los derechos sociales, económicos, culturales, no se encuentran aislado de los derechos civiles y políticos, al contrario existe una interrelación entre ambos,

- Esta interrelación es dinámica, flexible, holística, cualitativa, por consiguiente debe ser comprendida desde una visión complementaria y compleja de la realidad,

- La visión fragmentada y estructurada de los derechos humanos, que buscó brindar repuestas a desafíos de determinados momentos históricos, hoy día brinda paso al estudio desde una realidad interconectada, es decir, hoy los derechos humanos representan un bloque interdependiente, mediante el cual se debe generar sinergia por parte del Estado y de la Ciudadanía, para que los 
derechos humanos sean visibilizados como un cuerpo coherente del accionar humano,

- Por consiguiente, no deben percibirse que un determinado grupo de derechos, tiene mayor importancia sobre otro, todos son indispensables para el logro de un vivir bien en sociedad.

- Los derechos humanos, soberanía, globalización y deuda externa, son temas interconectados entre sí, lo cual índice en una correlación entre los mismos, la cual puede ser positiva si existe ciudadanía en capacidad de emprender acciones en progreso de su pueblo, será negativa en la medida que esta ciudadanía no exista y la sociedad se constituya en dependiente de agentes externos para trabajar en su desarrollo,

- Si se trastoca la soberanía, se violan los derechos humanos de las personas que habitan un determinado territorio, esta violación puede ser por el propio Estado o por Estados externos,

- Para ser soberanos es necesario contar con ciudadanos en conocimiento y cumplimiento de sus deberes y derechos constitucionales,

- La educación crítica, reflexiva, es la vía para formar ciudadanos soberanos,

- El Estado es el medio para proteger la soberanía mediante la generación del buen vivir por medio de otorgar al pueblo la mayor suma de felicidad posible,

- El Estado debe promover la independencia ciudadana y desde esta las diversas independencias como educativa, cultural, económica, tecnológica, como ejes fundamentales para el progreso integral de un país.

- La democracia y los derechos humanos se constituyen un entramado complejo, por cuanto sea el modelo de filosofía política que se desarrolle en un determinado país, será el manejo de los derechos humanos,

- Desde la visión representativa o protagónica de la democracia, la ciudadanía adopta roles diferentes, en el primero es de mayor pasividad y su actuación se articula mediante el voto y elección democrática, 
- Mientras que el segundo modelo, la ciudadanía tiene un papel de mayor protagonismo en la construcción y aplicación de las políticas públicas que procuren beneficiar al colectivo,

- Se puede generar un rol de receptor o emisor de los derechos humanos, según sea el modelo democrático que adopte la ciudadanía,

- La carta interamericana se constituye en un instrumento que según los intereses de quien la aplique, podría ser considerado una injerencia o no en la soberanía de un país,

- Los poderes geopolíticos pueden incidir en la aplicación de la carta interamericana en un determinado país, existiendo o no violación de los derechos humanos, siendo aún grave cuando existe tal violación y no es aplicada oportunamente.

- Los derechos humanos y la democracia, tienen una carga se subjetividad política, por lo tanto, es menester de la ciudadanía tener mayor participación protagónica para defender y promover realmente el tema de los derechos humanos.

- Los derechos humanos y la criminalidad, es un tema complejo, dado que se hacen juicios morales, jurídicos, sobre el acto final cometido por el criminal, lo cual es importante y debe hacerse, solo que en el fondo no se toman los correctivos necesarios para evitar que los escenarios que condujeron a tal acto no sean los que sigan ocasionando violación sistemática de los derechos humanos,

- Esto implica cumplir no solo con los derechos civiles, políticos, sino con los económicos, culturales, sociales, de un pueblo, por cuanto la integralidad de los mismos, permitirán trabajar en un bloque unificado hacia una real defensa y promoción de los derechos humanos,

- El terrorismo es una de las más viles expresiones de la violación de los derechos humanos, por cuanto se constituye en una guerra no convencional, no declarada, el cual toma por sorpresa a víctimas inocentes, lo cual genera violación de los derechos humanos en todas sus expresiones, 
- Los avances científicos cuando son usados en contra del ser humano, es decir, como medio de dominación del terrorismo, bandas criminales mundiales para el desarrollo de guerras convencionales y no convencionales, violan los derechos humanos, especialmente los principios de libertad, igualdad, justicia, respeto.

- Se debe trabajar en la formación de la ciudadanía sobre el tema de los derechos humanos, desde una visión compleja de los mismos, en este sentido, el Estado tiene el deber de brindar los mecanismos necesarios para la promoción y defensa de los derechos humanos, pero solo una ciudadanía formada, organizada, consciente del valor que representan la defensa de los derechos humanos, podrá transcender como modelo social - político para vivir en consonancia con lo planteado por los derechos humanos, en una justa defensa, promoción, pero sobre todo convivencia individual, colectiva, de los mismos.

\section{Referencias Consultadas}

1. Arnestein, S. (1971). La escalera de la participación ciudadana JAIP, vol. 35. No.4 pp. $216-224$.

2. Carta interamericana (2001). La democracia y el sistema interamericano. La democracia y los derechos humanos. Documento en línea. Disponible en: http://www.oas.org/OASpage/esp/Publicaciones/CartaDemocratica_spa.pdf. Consultado el 20-03-18.

3. Comisión de Derechos Humanos de Naciones Unidas, en 1993. Informe sobre el $49^{\circ}$ período de sesiones, New York,

4. Declaración de los Derechos Humanos (1948). Derechos humanos. Documento en línea. Disponible en: http://www.un.org/es/sections/issues-depth/humanrights/index.html. Consultado el 20-03-18.

5. Democracia participativa.net (2015) ¿Qué entendemos por democracia participativa. Documento en línea. Disponible en: https://democraciaparticipativa.net/documentos-data-a-referenda/fundamentosbasics/21-iquentendemos-por-democracia-participativa.html. Consultado el 8-418 
6. González, S. (1997). Soberanía y derechos humanos. Mexican Journal of Political and Social Sciences; Vol 41, No 170 (1997) Revista Mexicana de Ciencias Políticas y Sociales; Vol 41, No 170 (1997) 2448-492X 0185-1918. Documento en línea. Disponible en: http://www.revistas.unam.mx/index.php/rmcpys/article/viewFile/49301/44354.

Consultado el 22-03-18.

7. Maddison, A. (1998). Dynamic forces in capitalist development. Oxford: Oxford University press.

8. Martorano, J. (2017). Hablemos de líderes negativos. No de PRANES. Documento en línea. Disponible en: https://www.aporrea.org/actualidad/a241241.html. Consultado el 11-04-18.

9. Marshall, T. H. (1998). Ciudadanía y clase social, Madrid, Alianza Editorial.

10.OEA (2016). La carta interamericana. Documento en línea. Disponible en: http://www.oas.org/es/centro_noticias/comunicado_prensa.asp?sCodigo=D014/16. Consultado el 28-03-18.

11. Opazo, J. (2000), "Ciudadanía y democracia. La mirada de las ciencias sociales”, en Metapolítica, núm. 15, vol. 4, julio/septiembre, México, Centro de Estudios de Política Comparada A. C., Ediciones Educación y Cultura.

12. Red Europea sobre Deuda y Desarrollo (EURODAC, 1991). Deuda externa y derechos humanos. Documento en línea. Disponible en: https://www.derechos.org.ve/web/wp-content/uploads/informe_especial-8.pdf. Consultado el 28-03-18.

13.Vargas, A. (2013). Democracia representativa y democracia participativa. Documento en línea. Disponible en: http://www.elcolombiano.com/historico/democracia_representativa_y_democracia _participativa-PEec_239701. Consultado el 8-11-17

14. Villaseñor, I. (2015). La democracia y los derechos humanos: Una relación compleja. Documento en línea. Disponible en: http://www.scielo.org.mx/pdf/fi/v55n4/0185-013X-fi-55-04-01115.pdf. Consultado el 8-4-18

(C2018 por los autores. Este artículo es de acceso abierto y distribuido según los términos y condiciones de la licencia Creative Commons Attribution (http://creativecommons.org/licenses/by/4.0/). 